\title{
ESTIMATION OF NEW RELATIVE PERMEABILITY CURVES DUE TO COMPACTION CASE STUDY AT BACHAQUERO FIELD - VENEZUELA
}

\author{
Ta Quoc Dung ${ }^{(1)}$, Peter Behrenbruch ${ }^{(2)}$ \\ (1) University of Technology, VNU-HCM \\ (2) The Australian School of Petroleum \\ (Manuscript Received on November 05 ${ }^{\text {th }}, 2010$, Manuscript Revised October 13 ${ }^{\text {rd }}$, 2011)
}

\begin{abstract}
This paper is written to analyse the variation of water production due to compaction in a field in Venezuela. The producing water, after being analysed, was suspected not from aquifer. So where does the water come from? The results shows that pore structures of reservoir changed, and producing water is due to volume changes of immobile water and mobile water as the result of compaction. It means that relative permeability curves have changed when rock deforms.
\end{abstract}

\section{INTRODUCTION}

Studies of coupled flow-geomechanics simulations have received more and more attention due to their relevance to many problems in oil field development. Compaction and subsidence due to oil and gas production can be observed in several fields around the world such as Gulf of Mexico, North Sea, Venezuela. In Australia, compaction and subsidence problems were primarily documented in Gippsland basin. In accordance with compaction, reservoir properties changes are observed complicatedly. Several researches have been conducted to identify the impact of compaction to reservoir properties. Coupled reservoir simulation is used to examine compaction, subsidence in the reservoir and the impact to flow performance.

This paper is written to analyse the variation of water production due to compaction in a field in Venezuela. The producing water, after being analysed, was suspected not from aquifer. So where does the water come from? The authors suppose that pore structures of reservoir changed, and producing water is due to volume changes of immobile water and mobile water as the result of compaction. It means that relative permeability curves have changed when rock deforms.

The objectives of this paper are presented as following:
Overview methods to predict new irreducible water saturation $\left(\mathrm{S}_{\text {wir }}\right)$ due to compaction;

Applicable methods to create new relative permeability curve based on new endpoint data;

Analysis of water production due to compaction, and critical points of updating relative permeability curves.

Coupled reservoir simulation using an updated relative permeability curve will be applied to simulate properly a compaction reservoir in the Bachaquero field in Venezuela.

End-points in relatives permeability curve

\section{IRREDUCIBLE WATER SATURATION}

Water saturation is the fraction of water volume in the rock in respect of the total pore volume. Formation water always appears in reservoir formation. It is sea water trapped in rock matrix for a long time before the migration of other fluids, e.g. oil or gas. The distribution of water saturation is dominated by capillary, viscosity and gravity forces. The water saturation will be one hundred percent below free water level. In the transient zone, water saturation would be varied depending on capillary forces. Water saturation becomes irreducible water saturation, $\mathrm{S}_{\text {wir }}$ above transient zone.

Irreducible water saturation is the lowest water saturation, which is:

$$
S_{\text {wir }}=\frac{B V W i}{\phi_{t}}
$$

Trang 38 
Where: BVWi is irreducible Bulk Volume Water and $\phi_{t}$ is total porosity.

The magnitude of that saturation is governed by fluid densities, wettability, interfacial tension, pore size and geometry. As the effect of compaction, pore size and geometry will be changed, affecting the magnitude of irreducible water saturation. Generally, $S_{\text {wir }}$ would increase as the pore size decreases; however, that variation of $S_{\text {wir }}$ is not a simple linear function. The relationships of porosity and irreducible water saturation, specifically value of $\phi x S_{\text {wir }}$, have been studied by several authors.

Weaver (1958) is seen to be the first one considering constant value of $\phi x S_{\text {wir }}$ in the homogeneous carbonate with the uniform matrix. Later, in 1965, Buckles (1965) suggests the reciprocal relations between $\phi$ and $S_{\text {wir }}$ to be constant with the idealized system of spherical particles, requiring (1) the linear relationship between surface area and $S_{\text {wir }}$ and (2) hyperbolic relations between porosity and surface area. Morrow (1971) correlates irreducible water saturation of wetting phase with the "packing heterogeneity", which depends on the threedimensional distribution of grains and the consolidating cement. The author suggests that irreducible water saturations would be independent to particle sizes, but have high correlation with packing heterogeneity. The measured irreducible water saturation was then proposed to characterize the packing heterogeneity properties of reservoir rocks.

At the same time, Holmes et al. (1971) review comprehensively effects of rock, fluid properties and their relations to the fluid distribution of sandstone. The qualitative relations among surface area, average pore entry radius and $S_{\text {wir }}$ were established. There were some important points relating to the relations of $\mathrm{S}_{\text {wir }}$ and porosity in their study:

The surface area cannot be correlated with porosity as discussed by Buckles (1965); therefore, porosity cannot be combined in any simple form with $\mathrm{S}_{\mathrm{wir}}$.
The $S_{\text {wir }}$ basically has the negative correlation with the surface area and positive correlation with the average pore entry size.

The increase of cementation would generally cause the increase of surface area. As $S_{\text {wir }}$ increases with the increase of surface area, Swir will consequently increases as the result of the cementation increase.

The sandstones with large pore size will have small surface area and high average pore entry radius, hence will have low $S_{\text {wir }}$ value. Contrastingly, the smaller-pore-size rock will have higher tortuosities, high surface area, low average pore entry radius, and hence will have high irreducible water saturation.

Large scatter of data is observed when plotting porosity-surface area and porosity- $\mathrm{S}_{\mathrm{wir}}$, indicating the correlation between porosity and the latter properties not to be simple.

In conclusion, regarding to the variation of porosity, factors directly dominating changes of $S_{\text {wir }}$ are pore volume, surface area, average pore radius. Therefore, the relations of $S_{\text {wir }}$ and porosity are complicated. Direct relationship and its mathematical model have not available yet.

\section{PREDICTING THE VARIATION OF $\mathbf{S}_{\text {WIR }}$ ACCORDING TO THE VARIATION OF POROSITY}

This part will discuss the relationship which is briefly identified the dependence of irreducible water saturation on variation of porosity. Such relationship is attempted to derive based on the combination of the modified Carman-Kozeny's equation and the empirical relationship between permeability, porosity and irreducible water saturation.

A number of correlation equations between permeability, porosity and irreducible water saturation are suggested by several authors. The general empirical relationship is proposed by Wylie and Rose (1950), which are:

$$
\mathrm{k}=\frac{\mathrm{P} \phi^{\mathrm{Q}}}{\mathrm{S}_{\mathrm{wir}}^{\mathrm{R}}}
$$


where: $\mathrm{P}, \mathrm{Q}$, and $\mathrm{R}$ are parameters which are calibrated to fit the core data.

Based on the above general relationship, various relationships are proposed. Among them are the relationship from Timur (1968) based on 155 sandstone core measurements from different fields. Timur's expression is:

$$
\mathrm{k}=\frac{0.136 \phi^{4.4}}{\mathrm{~S}_{\text {wir }}^{2}}
$$

The general form of modified CarmanKozeny's equation expresses the correlation of permeability as the function of porosity, specific surface area, tortuosity and pore shape factor:

$$
\mathrm{k}=\frac{\phi^{3}}{\mathrm{~F}_{\mathrm{ps}} \tau^{2} \mathrm{~S}_{\mathrm{vgr}}^{2}(1-\phi)^{2}}
$$

where $F_{p s}, \tau$ and $S_{v g r}$ are pore shape factor, tortuosity and specific surface area.

The inversed relationship between tortuosity and porosity is suggested by several authors. Pape et.al (1999) study the fractal pore-space geometry and express such relationship as follows:

$$
\tau \approx \frac{0.67}{\phi}
$$

The combination of the (3), (4) and (5) gives:

$$
\mathrm{S}_{\mathrm{wir}}=0.247 \mathrm{~S}_{\mathrm{vgr}} \sqrt{\mathrm{F}_{\mathrm{ps}}} \frac{(1-\phi)}{\phi^{0.3}}
$$

When reservoir fluids are extracted, under the increment of overburden pressure, reservoir formation is compacted. The compaction process can be briefly divided into 2 phases:

Re-arrangement: Under overburden pressure, loosed grains are re-arranged to reduce pore volume between them. The tendency of the rearrangement is to reduce the exposed grain surface to fluid, hence reduces the specific surface area. However, as the definition from Tiab and Donaldson (2004), specific surface area is the total area exposed within the pore space per unit of grain volume, thus would increase if pore volume reduced. As the result, there should be no apparent relationship between specific surface area and porosity. Holmes et al (1971) also support that point when doing the study of lithology, fluid properties and their relationship to fluid saturation. With the assumption of insignificant changes of pore shape factor and specific surface area, according to equation (6) the changes of irreducible water saturation from $S_{\text {wirl }}$ to $S_{\text {wir2 }}$ when porosity reduces from $\phi_{1}$ to $\phi_{2}$ should be:

$$
S_{w i r 2}=S_{w i r 1}\left(\frac{\phi_{1}}{\phi_{2}}\right)^{0.3}\left(\frac{1-\phi_{2}}{1-\phi_{1}}\right)
$$

Because porosity reduces due to compaction, the new irreducible water saturation should become higher.

Grain-crushing: this stage happens after rearrangement stage when the grains are crushed. The mean grain diameter $\mathrm{d}_{\mathrm{gr}}$ and grain shape factor $\mathrm{K}_{\mathrm{gs}}$ significantly change. While the grain diameter decreases, the grain shape factor tends to increase to heighten the level of grain sphericity and roundness. Tiab and Donaldson (2004) suggest that $\mathrm{K}_{\mathrm{gs}}$ should approaches 6 when grains are perfectly spherical. The general relationship of the mean grain diameter, grain shape factor and specific surface area is suggested as following:

$$
\mathrm{S}_{\mathrm{vgr}}=\frac{\mathrm{K}_{\mathrm{gs}}}{\mathrm{d}_{\mathrm{gr}}}(8)
$$

The combination of (6) and (8) under the reduction of porosity due to grain crushing yields:

$$
S_{w i r 2}=S_{w i r 1}\left(\frac{\phi_{1}}{\phi_{2}}\right)^{0.3}\left(\frac{1-\phi_{2}}{1-\phi_{1}}\right)\left(\frac{K_{g s 2}}{K_{g s 1}}\right)\left(\frac{d_{g r 1}}{d_{g r 2}}\right)
$$

The slight increment of grain shape factor $\mathrm{K}_{\mathrm{gs}}$ and especially the reduction of mean grain diameter $d_{g r}$ cause irreducible water saturation to increase much higher in the grain crushing phase to compare with the increment of irreducible water saturation in the re-arrangement phase.

\section{WATER PRODUCTION DUE TO COMPACTION:}


The basic definition of water saturation is:

$$
\mathrm{S}_{\mathrm{w}}=\frac{\mathrm{V}_{\text {water }}}{\mathrm{V}_{\text {pore }}}
$$

Water becomes movable in a reservoir when water saturation is higher than irreducible water saturation. The movable water should be the difference between water saturation and irreducible water saturation timing pore volume.

In reservoir compaction, the pore volumes decrease, causing water saturation to increase.

$$
\frac{S_{\mathrm{w} 1}}{S_{\mathrm{w} 2}}=\frac{\mathrm{V}_{\text {pore } 2}}{\mathrm{~V}_{\text {pore1 }}}=\frac{\phi_{2}}{\phi_{1}}
$$

Therefore, the new water saturation due to porosity change should be:

$$
\mathrm{S}_{\mathrm{w} 2}=\mathrm{S}_{\mathrm{w} 1} \frac{\phi_{1}}{\phi_{2}}
$$

The irreducible water saturation, as discussed above, should also increases. However, the increase of water saturation is higher than the irreducible water saturation, which causes the water to be movable. The increments of irreducible water saturation are different depending on stages of compaction, causing the water production to vary. Water production due to compaction can be explained as the following figure:

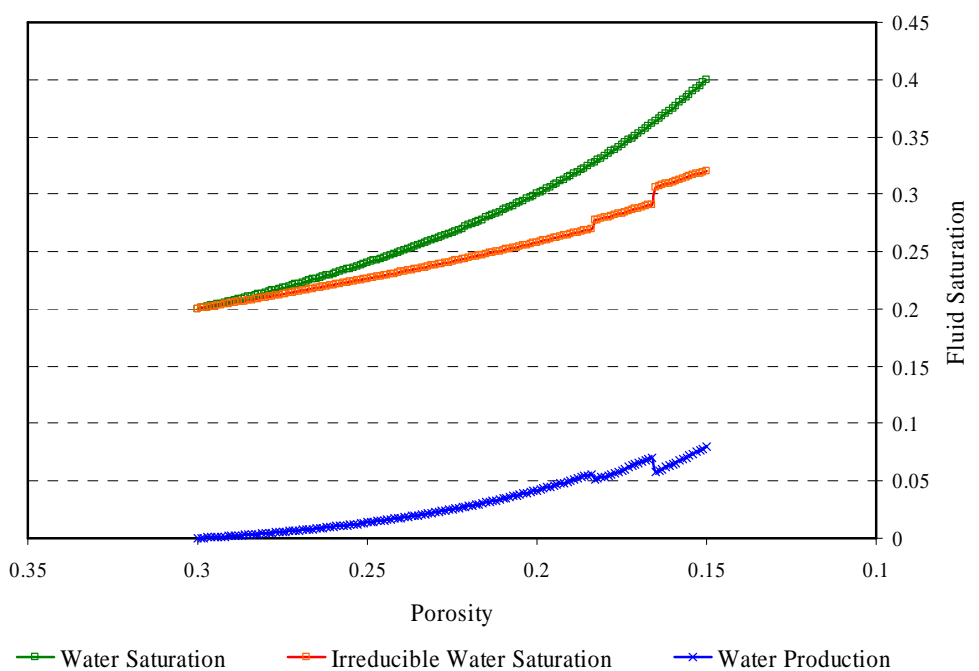

Figure 1. Water production due to compaction

Grain crushing phase is the phase that highly increase the irreducible water saturation. Depending on the level of crushing, water production can be reduced or even halted. Due to reservoir heterogeneities and the amount of fluid production, reservoir compaction occurs differently throughout the reservoir, causing water production to be various.

\section{RESIDUAL OIL SATURATION}

Residual oil saturation is defined as the fraction of volume of oil that can not be displaced over pore volume. In experiment, both residual oil saturation and irreducible water saturation depend on capillary pressure. However, for the experiment, the irreducible water saturation is determined from drainage capillary pressure curve. On the other hand, residual oil saturation is defined by the imbibition capillary curve. Nick, Valenti et al. (2002) showed that residual oil saturation is also governed by change of effective permeability which is mainly influenced by 
capillary pressure. Based on published data from Middle East Fields, they concluded that residual oil saturation is inversely proportional to permeability. It means that if total permeability reduces because of increasing effective stress in compacting reservoir, residual oil saturation will increase.

\section{Relative permeability models}

The permeability of a porous media is one important flow parameter associated with reservoir engineering. Permeability depends mainly on geometry of the porous system. If there are more than two fluids, permeability depends to any fluid not only on the geometry but also on saturation of each fluid phase, capillary pressure and other factors. There are numerous researches to create relative permeability curve based on both theoretical and empirical. The relative permeability curves are experimentally generated from either steady state or unsteady state experiment. Some experimental relationships common used in oil industry to create the relative permeability curves are summarised as following

\section{Original Brook - Corey relationship}

Brook and Corey (1966) observed under experimental conditions,

$$
\begin{aligned}
& \mathrm{k}_{\mathrm{ro}}=\left(\mathrm{S}_{\mathrm{e}}\right)^{\frac{2+3 \lambda}{\lambda}} \\
& \mathrm{k}_{\mathrm{rw}}=\left(1-\mathrm{S}_{\mathrm{e}}\right)^{2}\left(1-\mathrm{S}_{\mathrm{e}} \frac{2+\lambda}{\lambda}\right) \\
& \mathrm{S}_{\mathrm{e}}=\left(\frac{\mathrm{P}_{\mathrm{b}}}{\mathrm{P}_{\mathrm{c}}}\right)^{\lambda}
\end{aligned}
$$

Where: $\lambda$ is a number which characterizes the pore-size distribution. $\mathrm{P}_{\mathrm{b}}$ is a minimum capillary pressure at which the non wetting phase starts to displace the wetting phase. $P_{c}$ is a capillary pressure. $\mathrm{K}_{\mathrm{ro}}$ is oil relative permeability normalized to absolute plug air permeability and $\mathrm{K}_{\mathrm{rw}}$ is water relative permeability normalized to absolute plug air permeability

In real situations, relative permeability data are measured on cores cut with a variety of drilling mud, using extracted, restored state and preserved core samples. The relative permeability values were obtained from both centrifuge and waterflood experiments. So, each oil-water relative permeability data set was analysed and Brook - Corey equations were used to fit the oil and water relative permeability measurements. However, the forms of the Brook-Corey equations used do not always result in a good curve fit of the laboratory results. In addition, due to the difficulty of determining all parameters, the most useful model in petroleum industry used is the modified Brook and Corey model as shown below

Modified Brook and Corey relationship

$$
\begin{aligned}
& \mathrm{k}_{\mathrm{ro}}=\mathrm{k}_{\mathrm{ro}}^{\prime}\left(\frac{1-\mathrm{S}_{\mathrm{w}}-\mathrm{S}_{\text {or }}}{1-\mathrm{S}_{\mathrm{wir}}-\mathrm{S}_{\mathrm{or}}}\right)^{\mathrm{n}_{\mathrm{o}}} \\
& \mathrm{k}_{\mathrm{rw}}=\mathrm{k}_{\mathrm{rw}}^{\prime}\left(\frac{\mathrm{S}_{\mathrm{w}}-\mathrm{S}_{\mathrm{wir}}}{1-\mathrm{S}_{\mathrm{wir}}-\mathrm{S}_{\mathrm{or}}}\right)^{\mathrm{n}_{\mathrm{w}}}
\end{aligned}
$$

Where

$\mathrm{K}_{\mathrm{ro}}$ ': End point relative permeability normalized to oil absolute plug air permeability

$\mathrm{K}_{\mathrm{rw}}$ ': End point relative permeability normalized to water absolute plug air permeability

$$
\begin{aligned}
& \mathrm{S}_{\mathrm{or}} \text { : Residual oil saturation } \\
& \mathrm{S}_{\mathrm{w}} \text { : Water saturation } \\
& \mathrm{n}_{\mathrm{o}} \text { : Corey exponent to oil } \\
& \mathrm{n}_{\mathrm{w}} \text { : Corey exponent to water }
\end{aligned}
$$

This model can be applied for oil-water and gas-oil systems. The advantage of using this relationship is that the MBC model is smooth and extending an existing relative permeability curve. Normally, low Brook - Corey water exponents are associated with oil wet rock. The oil exponents decline from a value of about 5 at a permeability of 0.1 darcy to approximately 3 at permeability above 1 darcy. The exponents range between 1 and 4 with no clear trend based on permeability or reservoir lithology/zonation.

\section{Semi-empirical model}

Based on Carman-Kozeny's equation, Behrenbruch (2006) presented a new semi-

\section{Trang 42}


empirical model to predict a relative permeability curve as shown following

$$
\begin{aligned}
& k_{r w}= \frac{1014 m_{w}^{2} \phi_{e}^{3} S_{w}}{k} \\
& \mathrm{X}\left[\frac{S_{w}}{1-\phi_{e} S_{w}}-\frac{S_{w i r}}{1-\phi_{e} S_{w i r}}\right]^{2} \\
& k_{r o}=\frac{1014 m_{o}^{2} \phi_{e}^{3}\left(1-S_{w}\right)}{k} \\
& \mathrm{X}\left[\frac{1-S_{w}}{1-\phi_{e}\left(1-S_{w}\right)}-\frac{S_{o r}}{1-\phi_{e} S_{o r}}\right]^{2}
\end{aligned}
$$

In the above equations, $\mathrm{m}_{\mathrm{w}}$ and $\mathrm{m}_{\mathrm{o}}$ are considered as the slope of linear relationship in Carman-Kozeny's space. Clearly, effective porosity appears as a main parameter in relative permeability curves. Consequently, these equations are used in estimating the new permeability curve when porosity changes due to compaction.

To investigate the range of $\mathrm{n}_{\mathrm{w}}$ and $\mathrm{n}_{\mathrm{o}}$, Behrenbruch and Goda (2006) rearranged the $\mathrm{MBC}$ relationship as following

$$
\begin{aligned}
& \left(\frac{1-S_{\mathrm{w}}-S_{\text {or }}}{1-S_{\text {wir }}-S_{\text {or }}}\right)^{n_{o}-2}= \\
& \frac{\left(1-\phi\left(1-S_{\text {wir }}\right)\right)^{2}}{1-S_{\text {wir }}} \frac{1-S_{w}}{\left(1-\phi\left(1-S_{w}\right)\right)^{2}}
\end{aligned}
$$

\section{Table 1: Summary information}

$$
\begin{aligned}
& \left(\frac{S_{w}-S_{\text {wir }}}{1-S_{\text {wir }}-S_{\text {or }}}\right)^{n_{w}-2}= \\
& \frac{\left(1-\phi\left(1-S_{\text {or }}\right)\right)^{2}}{1-S_{\text {or }}} \frac{S_{w}}{\left(1-\phi S_{w}\right)^{2}}
\end{aligned}
$$

With parametric study, they showed that $n_{0}$ and $\mathrm{n}_{\mathrm{w}}$ varies in the range of $2.6-3.5$. These ranges have a maximum at 7 when porosity reduces to unity.

This study attempts to revaluate the range of $\mathrm{n}_{\mathrm{o}}$ and $\mathrm{n}_{\mathrm{w}}$ in MBC relationship. Our model using Monte Carlo Simulation (MCS) was run with all parameters required for the calculation used with normal distribution data as shown in Figure 2 and summarized in Table 1. Once the input data was determined, it replaced the input data in equations 20 and 21. Monte Carlo simulation was performed for 5,000 iterations.

The results show that with the normal distribution for input data (Figure 2), the mean of $\mathrm{n}_{\mathrm{o}}$ is about 2.7 and maximum and minimum $\mathrm{n}_{\mathrm{o}}$ are 3.37 and 2.14 , respectively. In addition, the standard deviation (Std) of $n_{0}$ is 0.28 . So, there is a $90 \%$ confidence interval where $n_{0}$ falls between $2.40-2.98$. On the other hand, the mean of $n_{w}$ is 2.61. The maximum and minimum $\mathrm{n}_{\mathrm{w}}$ are 3.32 and 2.09 , respectively (Table 3 ). In addition, Std of $n_{w}$ is 0.21 . As a result, there is a $90 \%$ confidence interval where $\mathrm{n}_{\mathrm{w}}$ falls between $2.27-2.97$. This distribution also indicates that due to the existence of uncertainty in input data, these interesting results tighten the result from Behrenbruch and Goda (2006) that samples were extracted randomly.

\begin{tabular}{lc}
\hline Workbook Name & Statistic to determination of no and nw \\
\hline Number of Simulations & 1 \\
\hline Number of Iterations & 5000 \\
\hline Number of Inputs & 4 \\
\hline Number of Outputs & 2 \\
\hline
\end{tabular}


Science \& Technology Development, Vol 14, No.M2- 2011

\begin{tabular}{ll}
\hline Sampling Type & Monte Carlo \\
\hline Simulation Start Time & $19 / 07 / 2007$ 16:55 \\
\hline Simulation Stop Time & $19 / 07 / 2007$ 16:55 \\
\hline Simulation Duration & $00: 00: 02$ \\
\hline Random Seed & 1587511621 \\
\hline
\end{tabular}
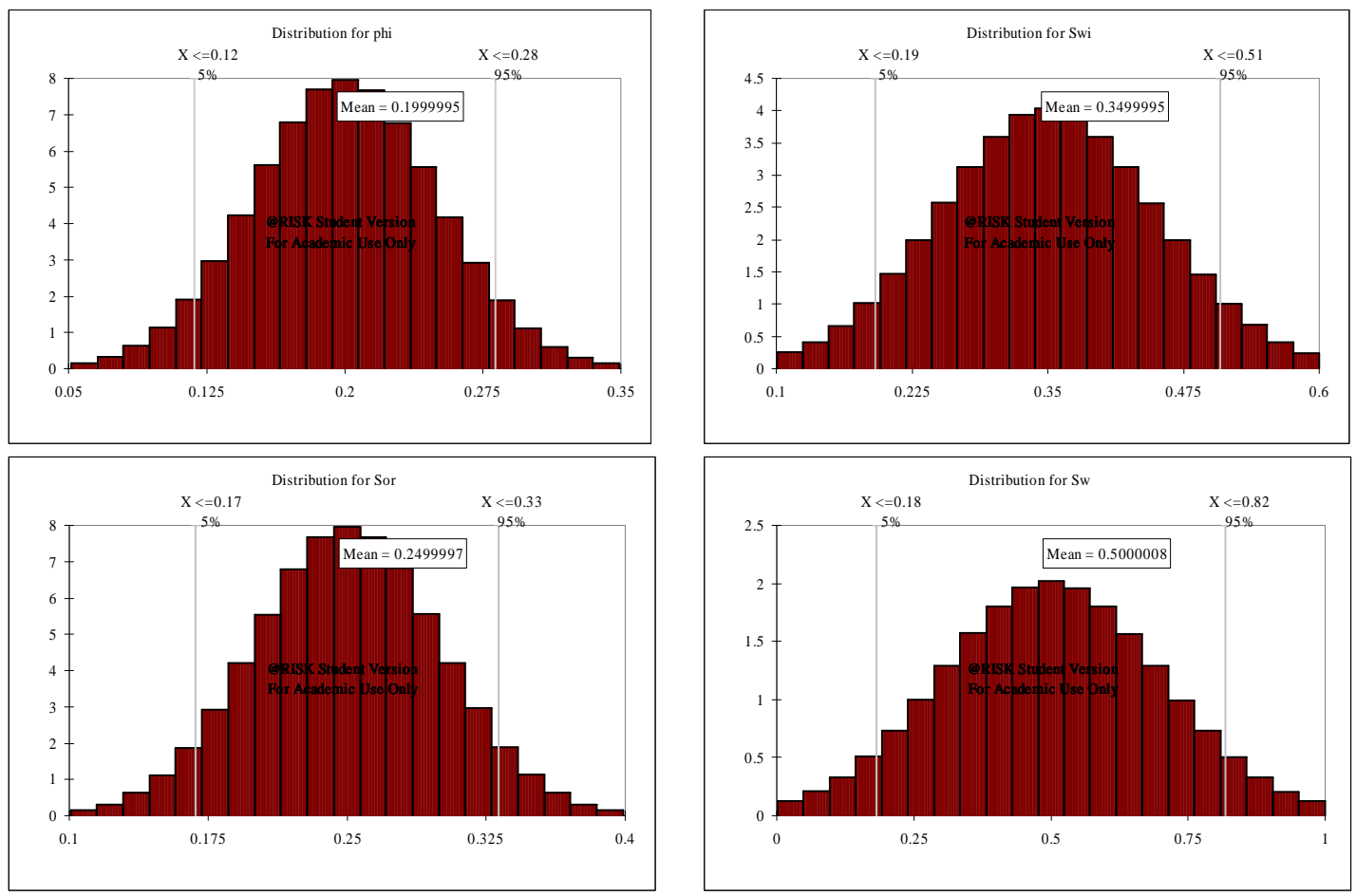

Figure 2. Distribution of input data for calculation of $\mathrm{n}_{\mathrm{o}}$ and $\mathrm{n}_{\mathrm{w}}$

Table 2: Summary of input data for calculation of $n_{o}$ and $n_{w}$

\begin{tabular}{llll}
\hline Name & Minimum & Mean & Maximum \\
\hline$\phi$ & 0.05 & 0.20 & 0.35 \\
\hline $\mathrm{S}_{\mathrm{w}}$ & 0.00 & 0.50 & 1.00 \\
\hline $\mathrm{S}_{\mathrm{or}}$ & 0.10 & 0.25 & 0.40 \\
\hline $\mathrm{S}_{\mathrm{wi}}$ & 0.10 & 0.35 & 0.60 \\
\hline
\end{tabular}



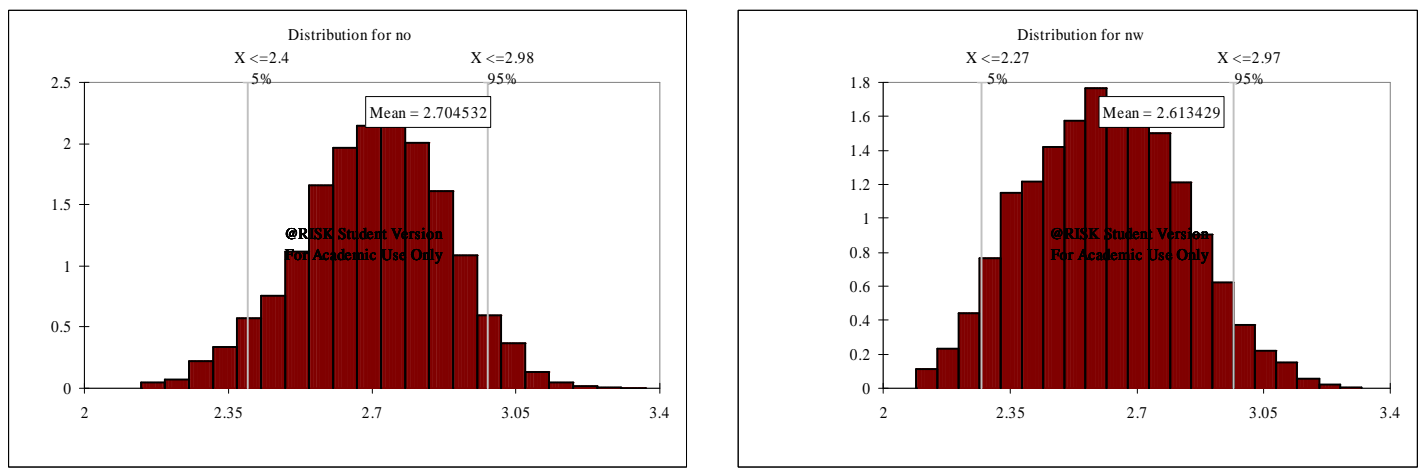

Figure 3. Distribution of $n_{o}$ and $n_{w}$

Table 3. Summary of $n_{o}$ and $n_{w}$

\begin{tabular}{lllll}
\hline Name & Minimum & Mean & Maximum & Std \\
\hline $\mathrm{n}_{\mathrm{w}}$ & 2.09 & 2.61 & 3.32 & 0.21 \\
\hline $\mathrm{n}_{\mathrm{o}}$ & 2.14 & 2.70 & 3.37 & 0.18 \\
\hline
\end{tabular}

A sensitivity analysis was conducted for both $\mathrm{n}_{0}$ and $\mathrm{n}_{\mathrm{w}}$. Figure 4 shows that the impact of all parameters on both $\mathrm{n}_{\mathrm{o}}$ and $\mathrm{n}_{\mathrm{w}}$. Simulation results are observed for $n_{w}$, with $S_{w i}$ having the biggest

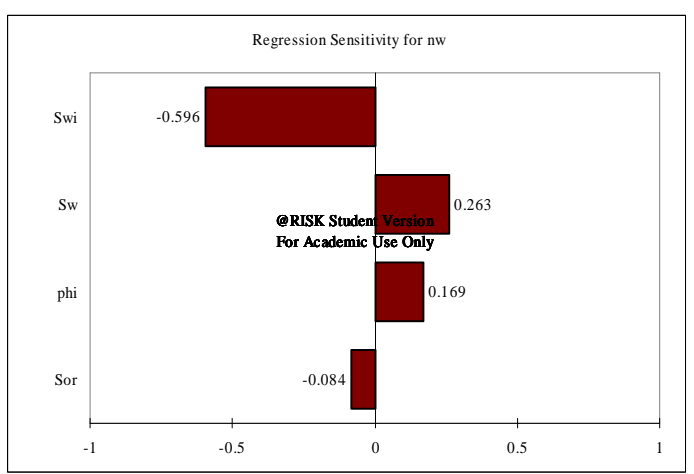

impact followed by $S_{w}$, porosity and $S_{\text {or }}$. It can be seen that the impact of $S_{w}$ uncertainty on $n_{o}$ is larger compared to the impact of $\mathrm{S}_{\mathrm{or}}, \mathrm{S}_{\mathrm{wi}}$ and porosity.

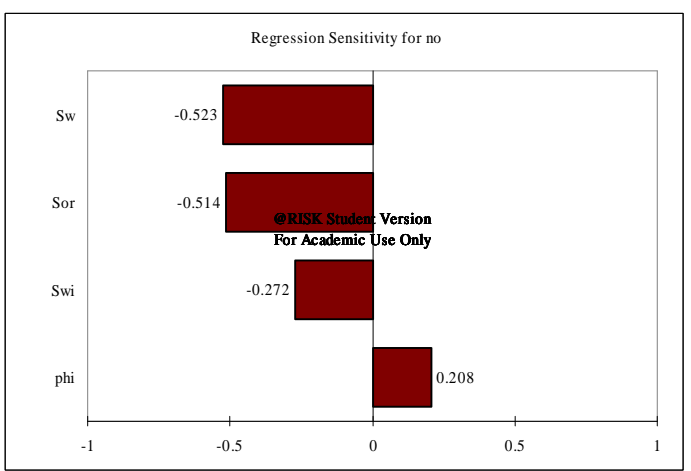

Figure 4. Tornado graph to invest the impact of parameters on both $\mathrm{n}_{\mathrm{o}}$ and $\mathrm{n}_{\mathrm{w}}$

Practical implementation

This part will investigate the compaction problem taking into account the principle of change in relative permeability curves applying in Lagoven area at the Bachaquero field in
Venezuela. The area is the one of four areas located along the lake Maracaibo both offshore and onshore. There has been subsidence since 1955. The subsidence prompted the construction of coastal dykes for protection against water flooding. Some observation sites have been 
installed to monitor ground subsidence. In most of the literatures, it becomes apparent from subsidence that compaction is the main energy drive in this field. In addition, compaction can change not only total porosity and absolute permeability in general but also can affect the wetting properties of rock. As a result, this phenomenon can impact dramatically on reservoir performance which is not easily modelled by conventional methods.

This case study will only investigate the change of relative permeability curve when porosity alters. The study concentrates on a reservoir engineering analysis to evaluate the effect of change of relative permeability curve on fluid production and interpretation the compaction behaviour.

\subsection{Description of Lagoven}

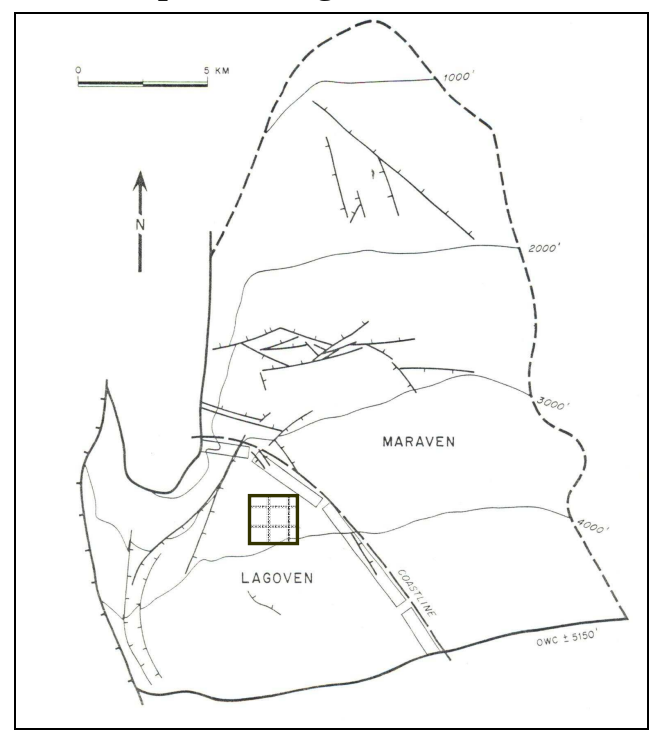

Figure 5. Structure map of Bachaquero reservoir and reservoir area grid

(Behrenbruch, van den Boer et al. 1979)

Lagoven area in Bachaquero field located in west coast of the Lake Maracaibo produces heavy oil (varying from $10^{\circ}-19^{\circ}$ API) from a Post Eocene reservoir since 1930 (Behrenbruch, van den Boer et al. 1979). Field location and coarse mesh of the investigated area (1/20 of field area) are presented in Figure 5. Field data until 1980 showed that there were about 500 well. The reservoir original pressure was about 2258 psi. The main production mechanisms that activates the Lagoven area is compaction drive that is especially outstanding in the unconsolidated sandstones of Bachaquero field. Compaction is a consequence of fluid pressure reduction in the reservoir during production. This causes all layers to "sink" into the reservoir, which is reflected as subsidence on the ground surface. Average subsidence until 80's was approximately $6 \mathrm{ft}$. However, compaction is an effective way to maintain the reservoir pressure and reduce water production, therefore, to increase total oil recovery.

\subsection{Material properties of reservoir}

The properties governing the geo-mechanical behaviour describing a linearly elastic porous medium of the reservoir are given in table 4.

Table 4. Material properties of reservoir in the simulation

\begin{tabular}{llll}
\hline Material properties & Symbol & Values & Field unit \\
\hline Initial porosity & $\phi$ & 031 & - \\
\hline Poison's ratio & $v$ & 0.21 & - \\
\hline Initial permeability & $\mathrm{K}$ & 178 & $\mathrm{mD}$ \\
\hline
\end{tabular}

Trang 46 
TẠP CHÍ PHÁT TRIỂN KH\&CN, TẬP 14, SỐ M2 - 2011

\begin{tabular}{llll}
\hline Young modulus & $\mathrm{E}$ & 65000 & $\mathrm{psi}$ \\
\hline Rock density & $\rho_{\mathrm{s}}$ & 128 & $\mathrm{p} / \mathrm{ft}^{3}$ \\
\hline Solid compressibility & $\mathrm{C}_{\mathrm{s}}$ & $25 \mathrm{E}-6$ & $\mathrm{psi}^{-1}$ \\
\hline Biot's constant & $\alpha$ & 0.95 & -
\end{tabular}

\subsection{Physical properties of pore fluid}

Physical properties of pore fluids can have a strong influence on the depletion pattern of a reservoir. Generally, the physical properties are a function of the composition of the fluid, the temperature, saturation and pressure. Therefore, the physical properties will vary throughout the reservoir as functions of the spatial location and

time as the reservoir conditions change. Below (Table 5 and 6), some key properties of the porefluid at investigated area in Lagoven field are given. The fluid properties used in the simulation are to be taken as mean value and are in no way to be taken to be an exact representation of the Lagoven fluid properties.

Table 5. Summary of fluid properties

\begin{tabular}{llll}
\hline Variables & Symbol & Initial value & Unit \\
\hline Vertical pressure gradient in oil & & 0.397 & Psi/ft \\
\hline Temperature at OWC & $\mathrm{T}$ & 129.6 & ${ }^{0} \mathrm{~F}$ \\
\hline Water compressibility (gas saturated) & $\mathrm{C}_{\mathrm{w}}$ & $3.5^{*} 10-6$ & $\mathrm{Psi}^{-1}$ \\
\hline Water compressibility in aquifer & $\mathrm{C}_{\mathrm{wa}}$ & $3^{*} 10-6$ & $\mathrm{Psi}^{-1}$ \\
\hline Oil compressibility & $\mathrm{C}_{\mathrm{o}}$ & $115^{*} 10-6$ & $\mathrm{psi}^{-1}$ \\
\hline Thickness of formation & $\mathrm{h}_{\mathrm{s}}$ & 637 & $\mathrm{ft}$ \\
\hline Average of thickness of oil sand & $\mathrm{h}$ & 300 & $\mathrm{ft}$ \\
\hline Oil viscosity & $\mu_{\mathrm{o}}$ & 23.00 & $\mathrm{cp}$ \\
\hline Initial pressure & $\mathrm{Pi}$ & 2258 & $\mathrm{Psi}$ \\
\hline Initial stress & $\mathrm{S}$ & 3941.60 & $\mathrm{Psi}$ \\
\hline
\end{tabular}

Table 6. Critical phase saturation and relative permeability data

\begin{tabular}{llll}
\hline Variables & Symbol & Initial value & Unit \\
\hline Connact water saturation & $\mathrm{S}_{\mathrm{wc}}$ & 0.16 & -- \\
\hline Relative oil permeability at $1-\mathrm{S}_{\mathrm{wc}}$ & $\mathrm{k}_{\mathrm{ro}}$ & 1 & -- \\
\hline Oil residual saturation & $\mathrm{S}_{\mathrm{ro}}$ & 0.2 & -- \\
\hline Relative water saturation at $\mathrm{S}_{\mathrm{ro}}$ & $\mathrm{k}_{\mathrm{rw}}$ & 0.3 & -- \\
\hline
\end{tabular}


Science \& Technology Development, Vol 14, No.M2- 2011

\begin{tabular}{llll}
\hline Initial water saturation & $\mathrm{S}_{\mathrm{w}}$ & 0.2 & -- \\
& & & \\
\hline Initial oil saturation & $\mathrm{S}_{\mathrm{o}}$ & 0.8 & -- \\
\hline
\end{tabular}

The new method based on empirical relationship (Behrenbruch and Goda 2006) will be used to predict the relative permeability curves. Figure 6 shows the authentic relative permeability curves from experiment measurement before production happening in Lagoven field. These curves are believed to be accurate because of good agreement between results obtained from MBC and new method.

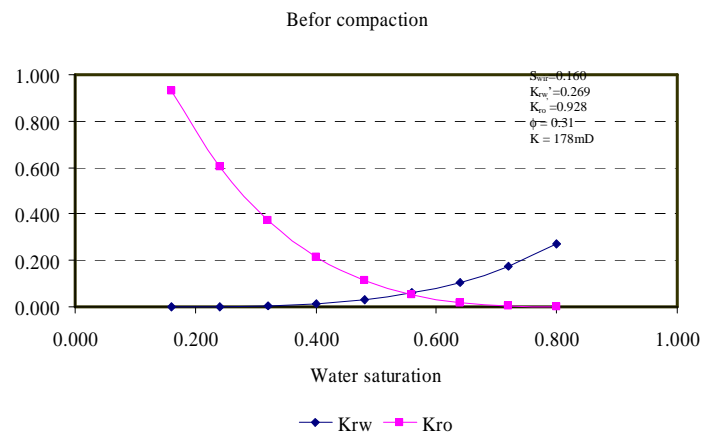

Figure 6. Relative permeability curve used in Lagoven field before sand rearrangement

\subsection{Interpretation of historic data}

The total oil production in Lagoven during this period amounted to $1.08 \times 10^{9} \mathrm{bbl}$. The total subsidence volume during the same period was about $0.374 \times 10^{9}$ bbl which corresponds to $35 \%$ of the oil production. This indicated that compaction drive was one the main production mechanisms. However, there was no relationship evidence between subsidence rate and production rate due to lacking of data.

Fortunately, looking at the water cut and subsidence derivative curves, it can be seen that there are 3 main periods when sand particles
The primary history data for Lagoven area are presented in Figure 7. The first well in the area was drilled in 1944. However, large numbers of wells were developed after 1953 and reached a level of about 500 wells in 1980. The total oil production rate in Lagoven during the 1955-1980 period varied between $60 \mathrm{Mb} / \mathrm{d}$ to $160 \mathrm{Mb} / \mathrm{d}$. The early peak of almost $160 \mathrm{Mb} / \mathrm{d}$ was reached in 1957. After that, the numbers of wells fluctuated because of well repair campaign at the end of 1958 and a drilling campaign in the mid 1960's.

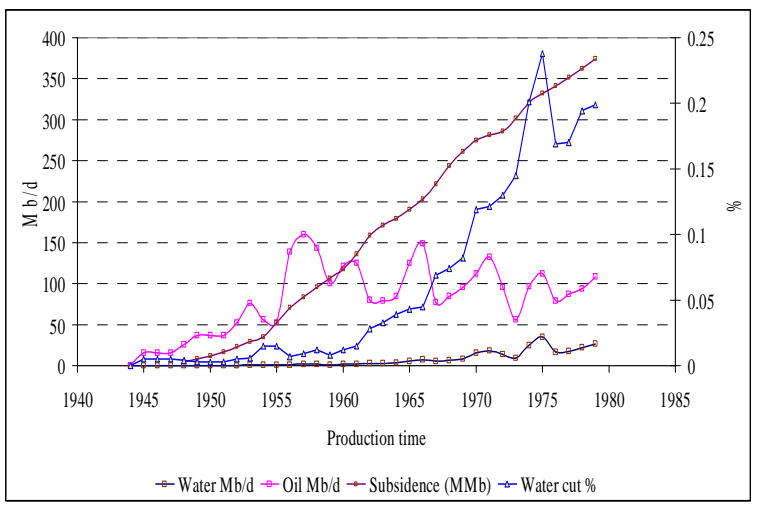

Figure 7. Historic data from Logoven field rearrange in reservoir within subsidence data (Figure 8). The first period happened when the large numbers of wells were developed after 1953. In this period, although water cut rate reduces the rate of subsidence increase significantly due to pore structure collapse. The situation recurs every 10 years. As a result, due to compaction or pore collapse, reservoir properties would change every period such as porosity, permeability. 


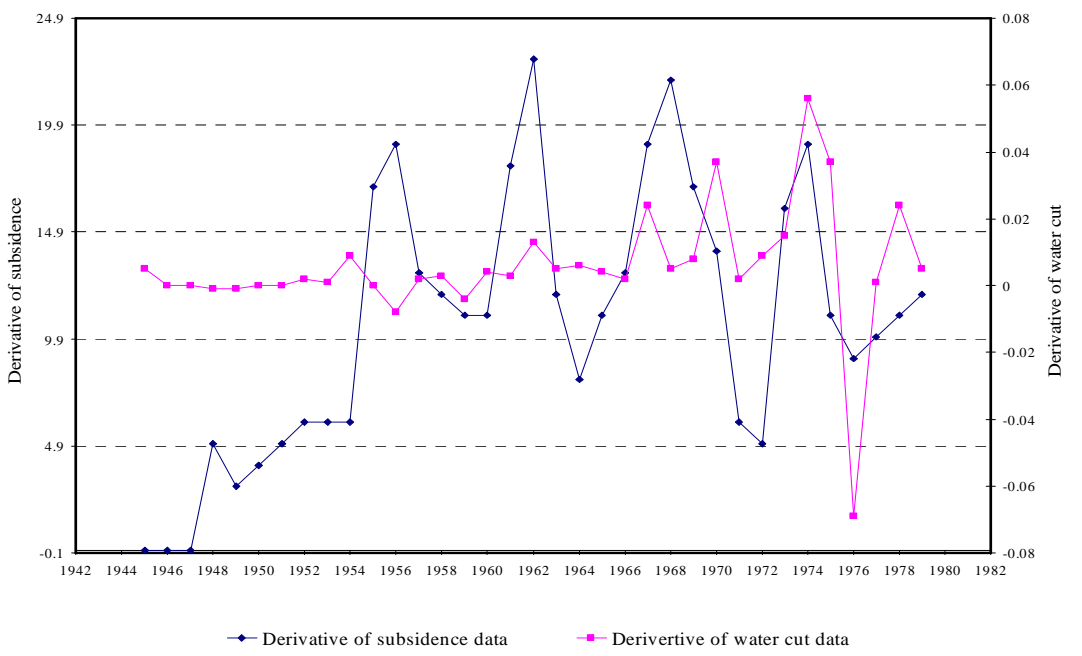

Figure 8. Water cut rate and subsidence rate of Lagoven field.

Eclipse Geomechanics (EclipseGM - Eclipse 300 ) is then used to allow the calculation of fluid flow within a reservoir and associated geomechanical processes with change of relative permeability curves. For the purposes of reservoir evaluation, it is necessary to identify the rock types to determine the precise rate of porosity and permeability decline with increasing stress for each rock type. Values of porosity and permeability will be predicted on a step-by-step basis for different values of change of net effective reservoir stress. This allows for prediction of porosity and permeability at different stages of reservoir development.
Knowledge of porosity at different values of in-situ stress will allow for the determination of new relative permeability curve resulting from the change of wetting surface (equations 18 and 19). New relative permeability curves are then updated in the coupled reservoir simulator for calculation of both rate of fluid production and compaction prediction. Figure 9 shows the new relative permeability curves which is used when reservoir compacts after introducing the large of number of wells in 1953. In this new relative permeability curves, $S_{w i r}$ increased from 0.16 to 0.168 according to reduction of porosity from 0.31 to 0.305 .

After compcation

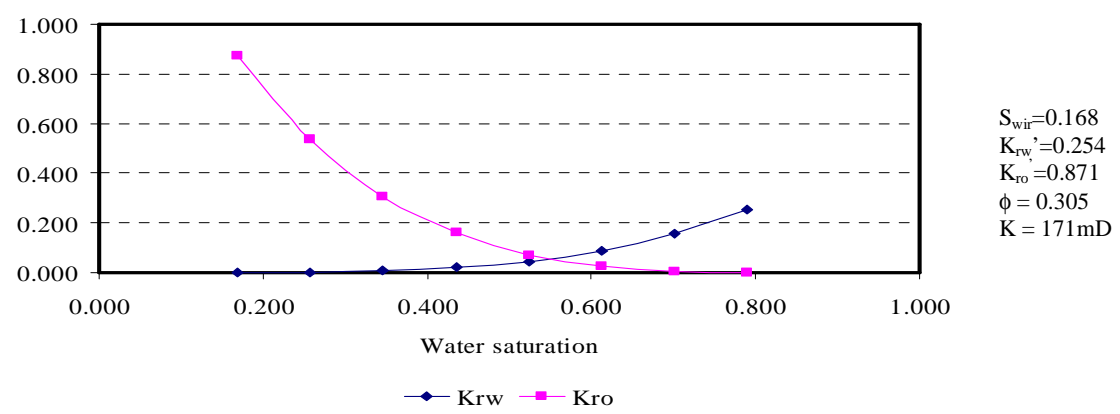

Figure 9. Relative permeability curve used in Lagoven field after sand rearrangement 


\subsection{Results and discussions}

Water production and water cut - modelling results

Figure 10 shows the difference of water production rate between conventional model and model with changing relative permeability. The first model which did not take account variation of relative permeability has a higher water

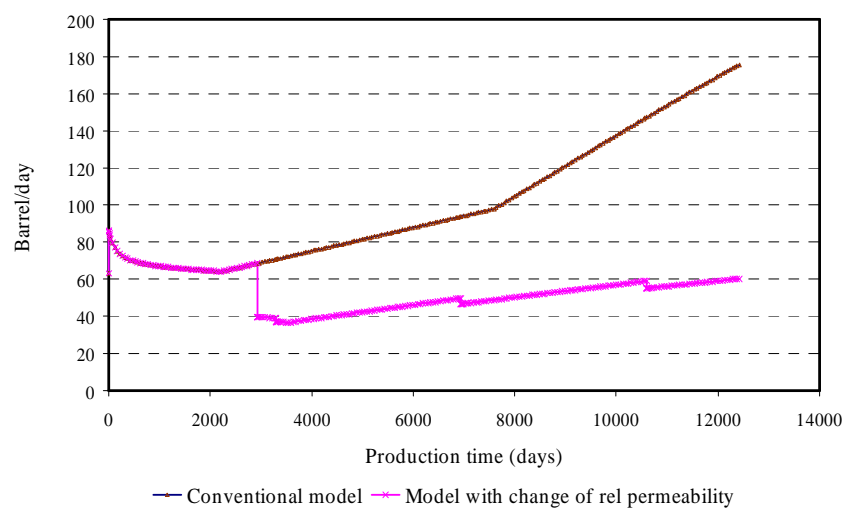

Figure 10. Water production rate due to change of relative permeability.

Figure 11 presented below shows the influence of change of relative curve on oil production and water production in two models. It can be obviously seen that oil production rate gets a peak when the reservoir was introduced more wells. In contrast, water production rate reduced because pore collapse when oil production rate adds to. It is also note that although the numbers of well increase double production rate. In contrast, the other model which was simulated with change of relative permeability with $S_{\text {wir }}$ higher has, as expected, a lower degree of water production. After 13000 days, the calculated water rate from the second model is approximately $70 \%$ lower compared to the result from the first model.

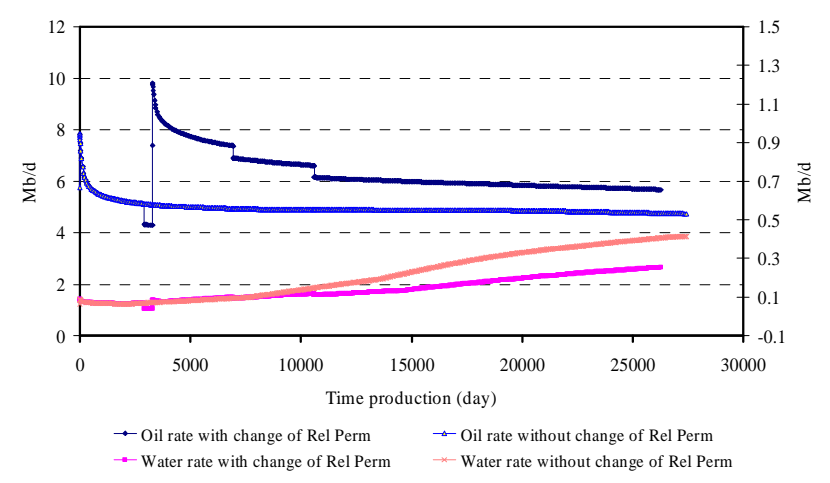

Figure 11. Prediction of oil production rate and water production rate Compaction prediction

\section{Trang 50}


EclipseGM output of displacement consists of three variables (ROCKDISX, ROCKDISY and ROCKDISZ), describing rock-displacement in $\mathrm{x}^{-}, \mathrm{y}-$, and $\mathrm{z}$-directions respectively. The displacements are written to disk at predetermined dates and times of the reservoir simulation. During the equilibration of the model and reduction of pore pressure, massive

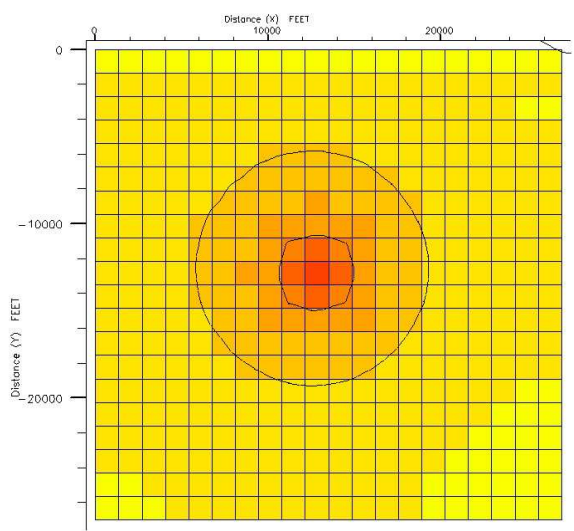

(a) deformations of the model can occur. The displacement patterns change from a circular bowl to a quasi-elliptical bowl (Figure 12a). The introduction of more wells also causes significant pressure depletion in the reservoir. As a result, compaction region dominated along the well direction (Figure 12b).

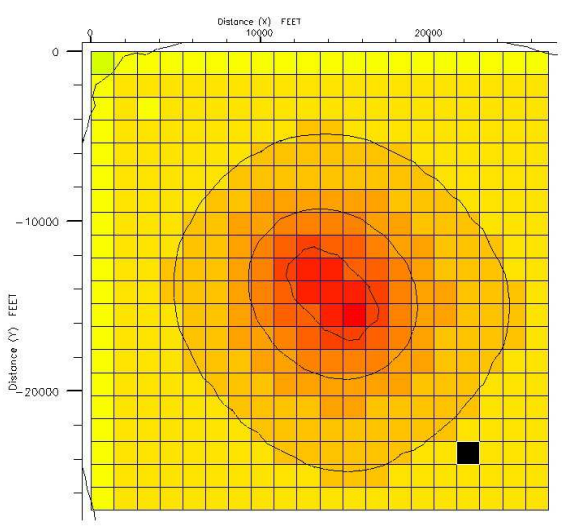

(b)

Figure 12. Compaction contour. The compaction profile was also computed.

Figure 13 presents the comparison between compaction profiles measured in a vertical cross-section that bisects the well location at the end of simulation in both models. The maximum compaction increases from $9.86 \mathrm{ft}$ to $10.20 \mathrm{ft}$ when compaction takes into account the behaviour of pore collapse. Both the maximum compaction values appear at the centre of bowl, also coinciding with the production well locations.

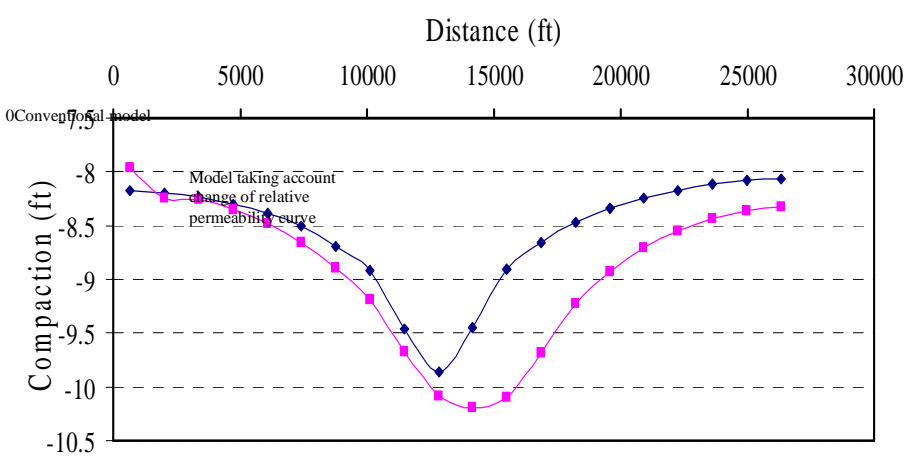

Figure 13. Compaction profiles

\section{CONCLUSIONS}

The research suggests that when reservoir formation is compacted, the compaction process can be briefly divided into 2 stages: rearrangement and sand-crushing. Based on Carmen-Kozeny's equation, new formulations to calculate to the new irreducible water saturation $\left(\mathrm{S}_{\mathrm{wir}}\right)$ due to 
compaction are developed. This is the most important result of this research. The new endpoint value is applicable for creating new relative permeability curve. Applying in case study in Venezuela field, it is shown that this theory has good applicability for simulation fluid production. Subsequently, in the context of compacting reservoir, accounting for irreducible water saturation, residual oil saturation, variation of effective porosity, altering of permeability and change of relative permeability curves should not ignored. Furthermore, the approach can be used to evaluate more accurately the extent of formation compaction and reservoir performance resulting from the variation of stress sensitive porosity/permeability.

With using Monte Carlo simulation, the new distribution of $n_{o}$ and $n_{w}$ is determined. The values of $n_{0}$ and $n_{w}$ are not only function of $S_{w}$ but also depend on $\mathrm{S}_{\mathrm{wir}}$, $\phi$ as well as $\mathrm{S}_{\mathrm{or}}$. Maximum and minimum of $n_{o}$ and $n_{w}$ are $(3.37,2.14)$ and $(3.32$, 2.29), respectively. So, the results of Monte Carlo simulation provide the decision maker with a better range of possible scenarios thus preempting and appropriate decision-making.

\title{
XÁC ĐỊNH ĐƯờNG CONG MỚI CỦA Độ THẤM TƯƠNG ĐỐI DO NÉN ÉP ĐỊA TĨNH KHI KHÄI THÁC DẦU
}

\author{
Tạ Quốc Dũng ${ }^{(1)}$, Peter Behrenbruch ${ }^{(2)}$ \\ (1) Trường Đại học Bách Khoa, ĐHQG-HCM
}

(2) Trường Dầu khí Úc

TÓM TĂT: Nghiên cưu trình bày kết qủa phân tích sụ biến đổi bất thương của luợng nước khi khai thác dầu trong via bị sụt lún tại Venezuela. Nước khai thác được xác định là không phải di chuyển tù̀ tầng nuớc đáy (aquifer). Kết luận cũng chỉ ra rằng cấu trúc lỗ rỗng thay đổi dẫn đến độ bão hòa nuớc du của đá chứa thay đổi và bổ sung vào hô̂n hợp chất lư khi khai thác. Nhu vậy, cấu trúc lô̂ rỗng thay đổi mạnh dẫn tới độ thấm pha tưong đối cũng thay đổi.

\section{REFERENCE}

[1]. Behrenbruch, P. and H. M. Goda (2006). Two-phase relative permeability prediction: a comparision of the modified Brook-Corey methodology with a new Carman-Kozeny based flow formulation. SPE 101150, SPE Asia Pacific Oil and Gas Conference and Exibition, Adelaide, Australia.

[2]. Behrenbruch, P., M. van den Boer, H. van Engen and J. van Lookeren (1979). Bachaquero field study- Part 6: Basic reservoir and well data. The Hague, the Netherlands, Shell Internationale Petroleum Maatschappij B.V.
[3]. Brooks, R. H. and A. T. Corey (1964). Hydraulic properties of poros media. Colorado, Colorado State University.

[4]. Brook, R. H. and A. T. Corey (1966). "Properties of porous media affecting fluid flow." Journal of Irrigation and drainage division 92(ASCE): 61-88.

[5]. Buckles, R. S. (1965). "Correlating and Averaging Connate Water Saturation Data." Journal of Canadian Petroleum Techonology 4(1): 42-52.

[6]. Holmes, M., K. D. Dreher and E. A.J. (1971). Lithology and Fluid Properties and Their Relations to the Distribution of Saturating Fluids in Sandstones. 46th Annual Fall Meeting of the Society of Petroleum Engineers of AIME, New Orleans. 
[7]. Morrow, R. N. (1971). "Small-Scale Packing Heterogeneities in Porous Sedimentary Rocks." AAPG Bulletin 55(3): 514-522.

[8]. Nick, P. V., R. M. Valenti and L. F. Koederitz (2002). A Unified Theory on Residual Oil Saturation and Irreduciable Water saturation. SPE 77545 - The SPE Annual technical Conference and Exhibition, San Antonia, Texas.

[9]. Pape, H., C. Clauser and J. Iffland (1999). "Permeability Presiction based on fractal pore-space geometry." Geophysics 64(5 (September-October 1999)): 1447-1460.

[10]. Tiab, D. and C. D. Donaldson (2004). Theory and Practice of Measuring Reservoir Rock and Fluid Transport Properties. USA, Petrophysics, Gulf Pub Co.
[11]. Timur, A. (1968). "An Investigation of Permeability, Porosity, and Residual Water Saturation Relationship for Sandstone Reservoirs." The Log Analyst.

[12]. Weaver, A. G. T. (1958). "An Approach to Carbonate Reservoir Evaluation Based on Mercury Injection." Oil in Canada(March 1958): 12-20.

[13]. Wyllie, M. R. J. and W. D. Rose (1950). "Some Theoretical Considerations Related to the Quantitative Evaluation of the Physical Characteristics of Reservoir Rock from Electrical Log Data." Journal of Petroleum Technology 189(1950).

[14]. Wyllie, M. R. J. and G. H. F. Gardner (1958). "The generalized Kozeny-Carman equation. Part 2 - a novel approach to problem of fluid flow." World oil: 210-228. 